\title{
Impact of Morphology of Conductive Agent and Anode Material on Lithium Storage Properties
}

\author{
Xiaobing Zhang ${ }^{1} \cdot \mathrm{Ji} \mathrm{Ma}^{1} \cdot$ Kezheng Chen ${ }^{1}$
}

Received: 24 April 2015/ Accepted: 30 May 2015/Published online: 30 June 2015

(C) The Author(s) 2015. This article is published with open access at Springerlink.com

\begin{abstract}
In this study, the impact of morphology of conductive agent and anode material $\left(\mathrm{Fe}_{3} \mathrm{O}_{4}\right)$ on lithium storage properties was throughly investigated. Granular and belt-like $\mathrm{Fe}_{3} \mathrm{O}_{4}$ active materials were separately blended with two kinds of conductive agents (i.e., granular acetylene black and multi-walled carbon nanotube) as anodes in lithium-ion batteries (LIBs), respectively. It was found that the morphology of conductive agent is of utmost importance in determining LIBs storage properties. In contrast, not as the way we anticipated, the morphology of anode material merely plays a subordinate role in their electrochemical performances. Further, the morphology-matching principle of electrode materials was discussed so as to render their utilization more rational and effective in LIBs.
\end{abstract}

Keywords Lithium-ion batteries $\cdot$ Morphology $\cdot$ Conductive agent $\cdot$ Anode material

\section{Introduction}

Long-lasting and green rechargeable energies are in high demand for solving the dilemma of global environmental pollution and energy shortage [1-3]. Among various renewable batteries, lithium-ion batteries (LIBs) have attracted increasing attention for their applications in portable electronics and electric vehicles in recent years [4-8]. For the requirement of high-performance LIBs, novel anode materials have become one of the research hotspots nowadays. Magnetite $\left(\mathrm{Fe}_{3} \mathrm{O}_{4}\right)$ is such a potential candidate because of its attractive theoretical capacity of $924 \mathrm{mAh} \mathrm{g}^{-1}$, nontoxicity, natural abundance, low cost, and high electronic conductivity $\left(2 \times 10^{4} \mathrm{~S} \mathrm{~m}^{-1}\right)[9,10]$. Along these lines, many efforts have been devoted to

Xiaobing Zhang and Ji Ma have contributed equally to this work.

Kezheng Chen

kchen@qust.edu.cn

1 Lab of Functional and Biomedical Nanomaterials, College of Materials Science and Engineering, Qingdao University of Science and Technology, Qingdao 266042, People's Republic of China obtaining high-performance $\mathrm{Fe}_{3} \mathrm{O}_{4}$ anode material with various morphologies, including hollow spheres [11, 12], arrays [12], belts [13], rods [14], fibers [15], etc. Although controlling the morphology of anode material may initially seem like a scientific curiosity, its impact goes far beyond esthetic appeal. For example, the porous morphology with higher surface area is much needed because of the intercalation capacities and affinities for lithium ions $\left(\mathrm{Li}^{+}\right)$to the more exposed holes in the surface, which could then shorten the diffusion length of $\mathrm{Li}^{+}$[16]. Besides, the inner pores also allow the material to effectively buffer the stress induced during the charge-discharge process [17]. Other desirable morphologies involve one-dimensional nanostructures, like nanorods and nanowires, which can offer a small diameter to enhance lithium diffusion and yet still provide a limited surface area to prevent excessive side reactions [18]. All of these morphological features of anode materials play a significant role in determining the discharge characteristics [19], and thus they are essential to apply in high-performance LIBs.

Apart from anode materials, the types and morphologies of conductive agents are other determinants to LIBs storage performances. Generally, granular carbon black [acetylene black $(\mathrm{AB})]$ is seen as a universal conductive agent with 
high conductivity. In addition, other types and morphologies of carbon species may be more desirable, and several research efforts have been conducted in this regard. Wang et al. [20] enabled $\mathrm{Ni}(\mathrm{OH})_{2}$ nanocrystals to grow on graphene sheets for potential energy storage applications. They found that graphene sheets with low oxidation are qualified to impart excellent electrical conductivity to the macroscopic ensemble of the composite materials (without the need of carbon black additives). The highly conducting graphene network allows rapid and effective charge transport between the $\mathrm{Ni}(\mathrm{OH})_{2}$ nanoplates in the macroscopic ensemble and the current collector, allowing for fast energy storage and release. Likewise, Liu et al. [21] utilized carbon-coated $\mathrm{ZnO}$ nanorod arrays as anode material without the extra addition of conductive agents. They found the coated carbon arrays not only ensure good electrical contact of $\mathrm{ZnO}$ with the current collector and enhance the charge transfer/ $\mathrm{Li}^{+}$transport, but also effectively alleviate the strains caused by the volume variation of $\mathrm{ZnO}$ nanorod cores and prevent the disintegration. Despite the progress achieved to date, the optimization of morphology of conductive agents with anode materials is not sufficiently discussed. And what is more, very little is known about the morphology-matching principle between the used conductive agents and anode materials.

In this study, we utilize $\mathrm{Fe}_{3} \mathrm{O}_{4}$ anode material (with granular and belt-like morphologies) and two kinds of conductive agent [i.e., granular $\mathrm{AB}$ and multi-walled carbon nanotube (MWNT)] as prototype systems to investigate their morphology impact on lithium storage performances. The selection criteria of multi-morphological conductive agents and anode materials are also proposed according to our electrochemical measurements and analyses.

\section{Experimental}

\subsection{Preparation of $\mathrm{Fe}_{3} \mathrm{O}_{4}$ Anode Material}

Analytical ferrous sulfate $\left(\mathrm{FeSO}_{4}\right)$ and sodium carbonate $\left(\mathrm{Na}_{2} \mathrm{CO}_{3}\right)$ were purchased from Sinopharm Chemical Reagent Co., Ltd. (China), and used as received without further purification. In a typical synthesis, $2 \mathrm{mmol}$ of $\mathrm{FeSO}_{4}$ was dissolved into $50 \mathrm{~mL}$ of deionized water at room temperature until a homogeneous solution was formed. After that, $1 \mathrm{~g}$ of $\mathrm{Na}_{2} \mathrm{CO}_{3}$ powder was added to the solution with continuous magnetic stirring. Then the mixture was transferred into a Teflon-lined stainless-steel autoclave with a capacity of $100 \mathrm{~mL}$ for hydrothermal treatment at $160{ }^{\circ} \mathrm{C}$ for $20 \mathrm{~h}$ (sample 1, marked as S160) and $200{ }^{\circ} \mathrm{C}$ for $8 \mathrm{~h}$ (sample 2, marked as S200) separately. The as-obtained precipitates were repeatedly washed with deionized water and ethanol, and finally dried at $60{ }^{\circ} \mathrm{C}$ for $6 \mathrm{~h}$.

\subsection{Characterization}

$\mathrm{X}$-ray diffraction (XRD) patterns were recorded on a powder X-ray diffractometer (Rigaku D/max-rA) equipped with a rotating anode and a $\mathrm{Cu} \mathrm{K}_{\mathrm{a} 1}$ radiation source $(\lambda=1.5406 \AA)$ at a step width of $0.02^{\circ}$. Field emission scanning electron microscope (FE-SEM) images were collected on a field emission scanning electron microscope (JEOL JSM-6700F). Transmission electron microscopy (TEM) images were performed on a JEM-2100 TEM with operating voltage at $200 \mathrm{kV}$.

\subsection{Electrochemical Measurements}

The electrochemical measurements were carried out at $25{ }^{\circ} \mathrm{C}$ using 2032 coin-type cells with pure lithium metal as the counter and reference electrodes. The working electrode consists of active material (as-synthesized $\mathrm{Fe}_{3} \mathrm{O}_{4}$ products), conductive agents ( $\mathrm{AB}$ or MWNT), and sodium carboxymethyl cellulose binder (CMC, 800-1200 mPa s, DS 0.7) in a weight ratio of 60: 20: 20 , using deionized water as the dispersion medium. The mixture was spread on a $\mathrm{Cu}$ foil and dried under vacuum at $120^{\circ} \mathrm{C}$ for $8 \mathrm{~h}$. The electrolyte used was $1.0 \mathrm{~mol} \mathrm{~L}^{-1} \mathrm{LiPF}_{6}$ in a mixture of ethylene carbonate and dimethyl carbonate (1: 1 by volume). Cell assembly was carried out in an Ar-filled glove box with the concentrations of moisture and oxygen below $1 \mathrm{ppm}$. The cells were cycled at different current rates of $0.2,0.5,1,2$, and $5 \mathrm{C}\left(1 \mathrm{C}=924 \mathrm{~mA} \mathrm{~g}^{-1}\right)$ between 0.01 and $3 \mathrm{~V}$ using a LAND battery tester. Electrochemical impedance spectroscopy (EIS) measurements were carried out on a CHI660D electrochemical workstation by applying a sine wave with an amplitude of $10.0 \mathrm{mV}$ over a frequency range of $100 \mathrm{kHz}$ to $10 \mathrm{mHz}$. The voltages mentioned in this study were referred to a $\mathrm{Li} / \mathrm{Li}^{+}$redox couple.

\section{Results and Discussion}

The chemical composition of the as-prepared S160 and S200 products is shown in Fig. 1a, in which all the diffraction peaks of each product can be unambiguously indexed to the cubic structure of $\mathrm{Fe}_{3} \mathrm{O}_{4}$ (JCPDS No. 65-3107). The SEM images in Fig. 1d, e clearly show the distinct morphology difference between these two products, in which S160 and S200 are of belt-like and polyhedral morphologies, respectively. Upon closer scrutiny, most $\mathrm{Fe}_{3} \mathrm{O}_{4}$ belt is tens of microns long, ca. 100-nm wide and ca. 10-nm thick (Fig. 1d). In contrast, the polyhedral 

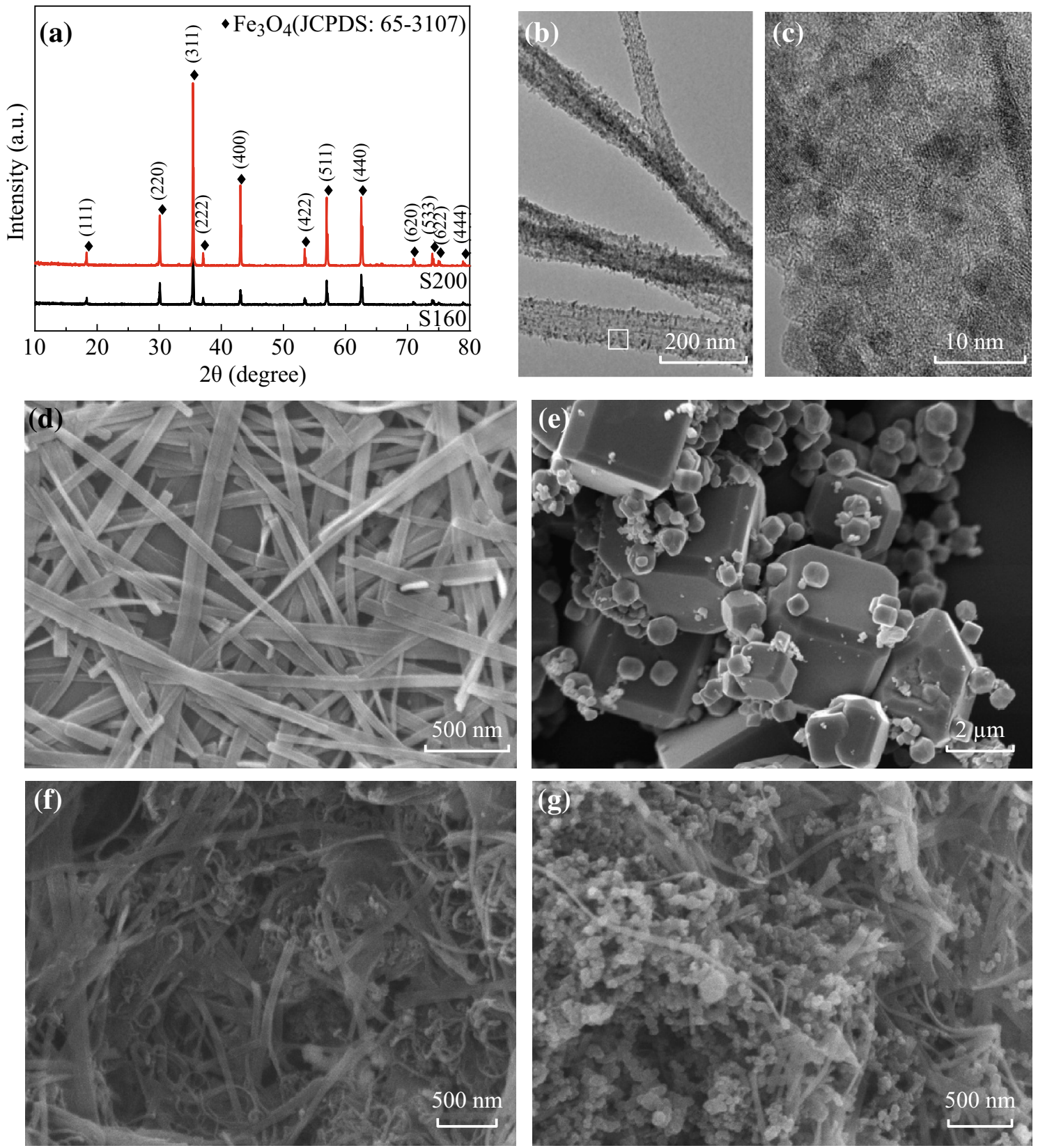

Fig. 1 a XRD patterns of $\mathrm{Fe}_{3} \mathrm{O}_{4}$ products prepared at $160{ }^{\circ} \mathrm{C}$ for $20 \mathrm{~h}(\mathrm{~S} 160)$ and $200{ }^{\circ} \mathrm{C}$ for $8 \mathrm{~h}$ (S200). b A typical TEM image of belt-like $\mathrm{Fe}_{3} \mathrm{O}_{4}$ products. c HRTEM image of the belt region marked with a black pane in panel b. SEM images of $\mathrm{Fe}_{3} \mathrm{O}_{4}$ products prepared at $\mathbf{d} 160{ }^{\circ} \mathrm{C}$ for $20 \mathrm{~h}$ and $\mathbf{e} 200{ }^{\circ} \mathrm{C}$ for $8 \mathrm{~h}$. SEM images of belt-like $\mathrm{Fe}_{3} \mathrm{O}_{4}$ mixed with $\mathbf{f}$ MWNT and $\mathbf{g}$ acetylene black

$\mathrm{Fe}_{3} \mathrm{O}_{4}$ product is less uniform in size, ranging from 1 to $4 \mathrm{~m}$ (Fig. 1e). Close inspection of the representative TEM image of $\mathrm{Fe}_{3} \mathrm{O}_{4}$ belt in Fig. 1b reveals that its surface is rough in texture, and is full of small deposited particles of similar sizes. The HRTEM image in Fig. 1c further demonstrates the relatively poor crystallinity of the belt, in which the finite-sized $\mathrm{Fe}_{3} \mathrm{O}_{4}$ particles of ca. $5 \mathrm{~nm}$ spread over the amorphous belt-matrix. Nonetheless, due to the size range of these particles, there are no obvious XRD peaks broadening in Fig. 1a. Even the belt product has relatively poor crystallinity, most of them are still crystalline.

In order to study the impact of morphology of $\mathrm{Fe}_{3} \mathrm{O}_{4}$ and conductive agent on lithium storage properties, we utilize S160 and S200 mixed with two kinds of conductive agents (i.e., AB and MWNT) to assemble four different half-cells. Separately, the charge-discharge cycling was carried out for S160@MWNT (2.04 mg)/Li, S160@AB (2.22 mg)/Li, S200@MWNT (2.1 mg)/Li, and S200@AB (2.4 mg)/Li cells in the voltage window of $0.01-3 \mathrm{~V}$ at $0.2 \mathrm{C}$ rate. The 
voltage versus capacity profiles are shown in Fig. 2. During the 1 st cycle, the voltage plateau appears at $\sim 0.7 \mathrm{~V}$ mainly due to the reduction of $\mathrm{Fe}^{3+}$ and $\mathrm{Fe}^{2+}$ to $\mathrm{Fe}^{0}$, and then the curve slopes down to the cut voltage of $0.01 \mathrm{~V}$, which are typical characteristics of voltage trends for the $\mathrm{Fe}_{3} \mathrm{O}_{4}$ electrodes [22-26]. The subsequent discharge curves of these four cells are all different from the first ones, suggesting drastic, $\mathrm{Li}^{+}$-driven, structural or textural modifications [27]. Generally, the lithium storage mechanism of metal oxides is based on a redox conversion reaction, where the metal oxides are reduced to metallic nanocrystals dispersed in $\mathrm{Li}_{2} \mathrm{O}$ matrix upon lithiation and then reversibly restored to their initial oxidation states during delithiation [28]. Along this line, electrochemical lithium storage in $\mathrm{Fe}_{3} \mathrm{O}_{4}$ follows the conversion reaction mechanism described by Eq. (1): [27, 29].

$\mathrm{Fe}_{3} \mathrm{O}_{4}+8 \mathrm{Li}^{+}+8 \mathrm{e}^{-} \leftrightharpoons 4 \mathrm{Li}_{2} \mathrm{O}+3 \mathrm{Fe}$.

The formation of $\mathrm{Li}_{2} \mathrm{O}$ and $\mathrm{Fe}$ in the forward reaction is thermodynamically favorable during the discharge process. However, the extraction of $\mathrm{Li}^{+}$ion from $\mathrm{Li}_{2} \mathrm{O}$ in the reverse process is more difficult, which suggests that a certain extent of irreversibility is inevitable. This conversion reaction provides the dominant contribution to the lithium storage capacity of $\mathrm{Fe}_{3} \mathrm{O}_{4}$ material and gives rise to a high initial discharge capacity of 1417, 1163, 1097, and $970 \mathrm{mAh} \mathrm{g}^{-1}$ for S160@MWNT/Li, S160@AB/Li, S200@MWNT/Li, and S200@AB/Li cells, respectively, corresponding to $12.3,10.1,9.5$, and 8.4 mol consumption of $\mathrm{Li}$ per mole of $\mathrm{Fe}_{3} \mathrm{O}_{4}$ anode material. A reversible charge capacity of $859,224,528$, and $305 \mathrm{mAh} \mathrm{g}^{-1}$ can be delivered after the 5th cycle, which leads to irreversible capacity loss of $39.4,80.7,51.9$, and $68.6 \%$ for S160@MWNT/Li,S160@AB/Li,S200@MWNT/Li, and S200@AB/Li cells, respectively. Such initial irreversible capacity loss is commonly ascribed to the formation of solid-electrolyte interface layer and some other side reactions [30].

The cycling performances of these cells are depicted in Fig. $4 \mathrm{a}$ at $0.2 \mathrm{C}$ rate between 0.01 and $3.0 \mathrm{~V}$. From the 5 th cycle onward, S160@MWNT/Li cell exhibits the most excellent cyclic capacity retention of $970 \mathrm{mAh} \mathrm{g}^{-1}$ after 50th cycle. Following that, in order, are S200@MWNT/Li, S200@AB/Li, and S160@AB/Li cells with capacities of
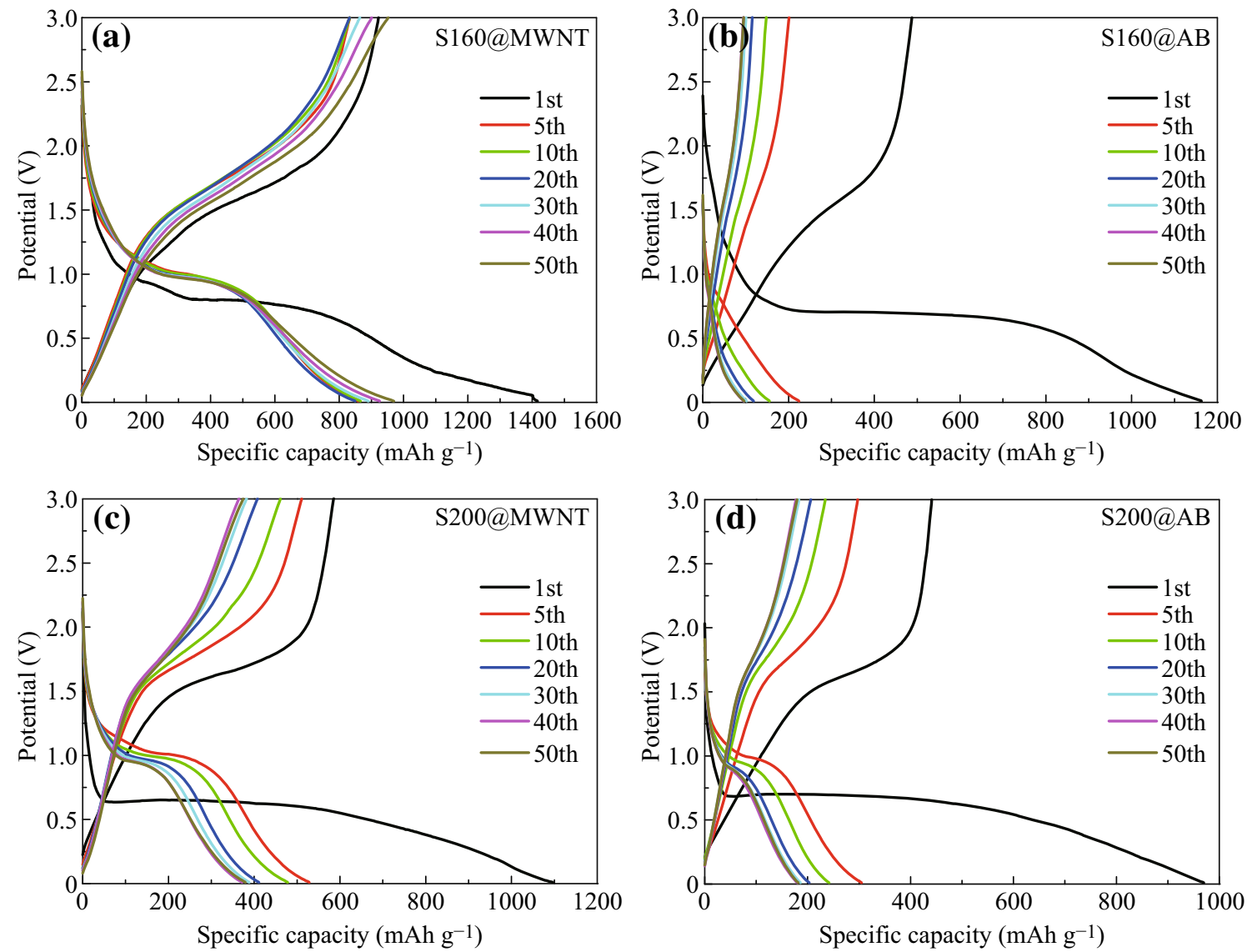

Fig. 2 Charge-discharge voltage profiles of a S160@MWNT (2.04 mg)/Li, b S160@AB (2.22 mg)/Li, c S200@MWNT (2.1 mg)/Li, and d S200@ AB $(2.4 \mathrm{mg}) / \mathrm{Li}$ cells cycled between 0.01 and $3 \mathrm{~V}$ at $0.2 \mathrm{C}$ rate 
380, 182, and $96 \mathrm{mAh} \mathrm{g}^{-1}$ after 50th cycle, respectively. Collectively, the capacity retention of $\mathrm{Fe}_{3} \mathrm{O}_{4}$ is somewhat disappointing because of the aggregation of $\mathrm{Fe}_{3} \mathrm{O}_{4}$ particles during cycling and large volume variation $(>200 \%)$ [27, 31]. This point can be confirmed by the SEM images of active materials in S160@AB/Li, S200@MWNT/Li, and S200@AB/Li cells after 50th-cycled capacity retention in Fig. 3. It shows that the original shape of $\mathrm{Fe}_{3} \mathrm{O}_{4}$ particles can hardly be distinguished due to their aggregation and volume expansion. More importantly, Fig. 4a strongly indicates that the morphologies of anode material and conductive agent have critical impact on LIBs cycling performances. It is unanimously accepted that the approaches for enhancing $\mathrm{Li}^{+}$and electron transport kinetics in LIBs include designing electrode materials with high $\mathrm{Li}^{+}$ diffusion constants and coating the electrolytically active material with a conductive layer to improve electron transport. Moreover, it has often been taken that reductions in the characteristic dimensions of the electrolytically active material are more effective in improving LIBs cycling performance than increases in ion diffusivity $D$, because the characteristic time constant $t$ for diffusion is proportional to the square of the diffusion length $L$ (i.e., $t \sim L^{2} / D$ ). Along this line, nanoscale electrodes have exceptionally shorten $\mathrm{Li}^{+}$and electron transport lengths. Therefore, the ideal electrode architecture for providing efficient $\mathrm{Li}^{+}$and electron transport should consist of a three-dimensional interpenetrating nano-network of $\mathrm{Li}^{+}$ and electron pathways. This is the exact case for S160@MWNT/Li cell in our study. As shown in Fig. 1f, the intertwined belt-like $\mathrm{Fe}_{3} \mathrm{O}_{4}$ and tubular MWNT provide effective $\mathrm{Li}^{+}$channel and rapid electron channel, respectively. As such, the recombination of $\mathrm{Li}^{+}$and electron can be greatly suppressed, and thus the efficient separation of positive and negative charges is typically achieved, resulting in its superior cycling performance. In contrast, the capacity retention of the other three cells is much inferior, presumably because of their entangled $\mathrm{Li}^{+}$and electron pathways.
To further validate the above statements, rate capabilities of S160@MWNT (1.86 mg)/Li, S160@AB (2.04 mg)/ $\mathrm{Li}, \quad$ S200@MWNT $(2.34 \mathrm{mg}) / \mathrm{Li}, \quad$ and $\quad$ S200@AB $(1.92 \mathrm{mg}) / \mathrm{Li}$ cells were conducted in the voltage range of 0.01 and $3 \mathrm{~V}$ at different cycling rates (with the same rates for both charge and discharge). Figure $4 b$ shows the S160@MWNT/Li cell exhibits the most superior rate capability, the next is S200@MWNT/Li cell, followed by S200@AB/Li and S160@AB/Li cells, which is in the same priority order as their cycling performances. Notably, the cyclability and rate capability of MWNT-involved cells (i.e., S160@MWNT/Li and S200@MWNT/Li cells) greatly outperform those of $\mathrm{AB}$-involved cells (i.e., S160@AB/Li and S200@AB/Li cells). This is because micron-sized soft MWNT not only facilitates the rapid and effective electron transport between electrode materials and the current collector, but also tightly twists and traps the active material, so that the strain caused by the volume variation of $\mathrm{Fe}_{3} \mathrm{O}_{4}$ during charge-discharge cycles can be effectively alleviated. This observation strongly evidences that the morphology of conductive agent, rather than that of anode material, is of utmost importance in determining LIBs storage performances. More specifically, if the topology of electronic pathways is such that all the particles of conductive agent are effectively wired, much faster charging and discharging rates are achieved, and thus leading to superior cyclability and rate capability. Otherwise, even though the morphology of $\mathrm{Fe}_{3} \mathrm{O}_{4}$ anode material is conducive for $\mathrm{Li}^{+}$ions to travel (e.g., $\mathrm{S} 160 @ \mathrm{AB} / \mathrm{Li}$ cell), the electrochemical properties of such cells are inferior even at low current densities (Fig. 4).

Based on the above discussion, if the morphology of conductive agent of each cell is identical, the electrochemical performances of these cells are mainly determined by the morphology of anode material. However, the morphology of anode material plays a subordinate role on the LIBs storage performance. For instance, by using the same type of MWNT conductive agent, the cyclability and rate capability of S160@MWNT/Li cell is much superior
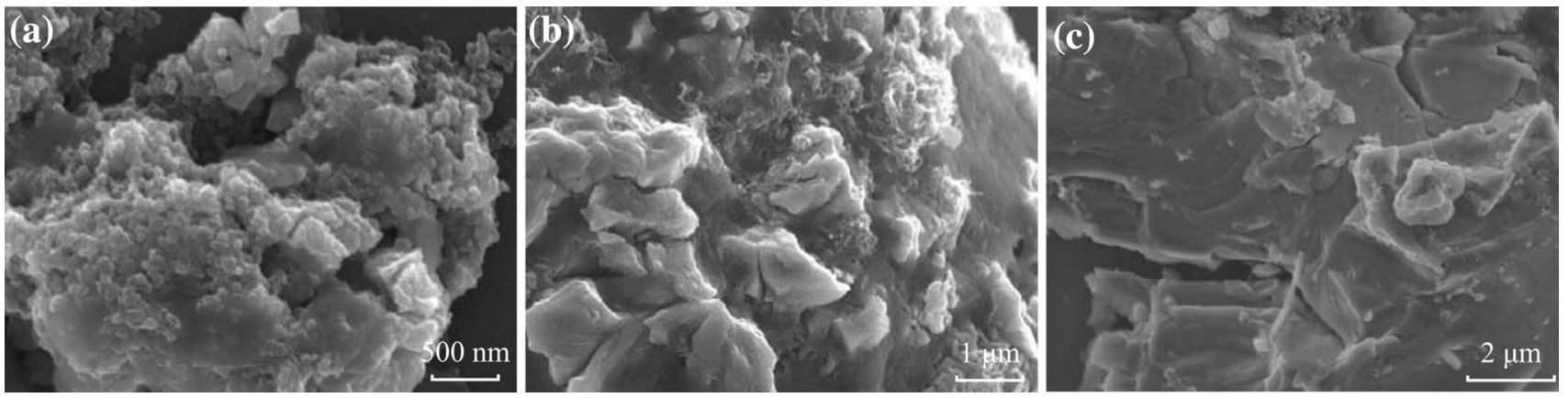

Fig. 3 SEM images of active materials in a S160@AB/Li, b S200@MWNT/Li, and c S200@ AB/Li cells after 50th-cycled capacity retention 

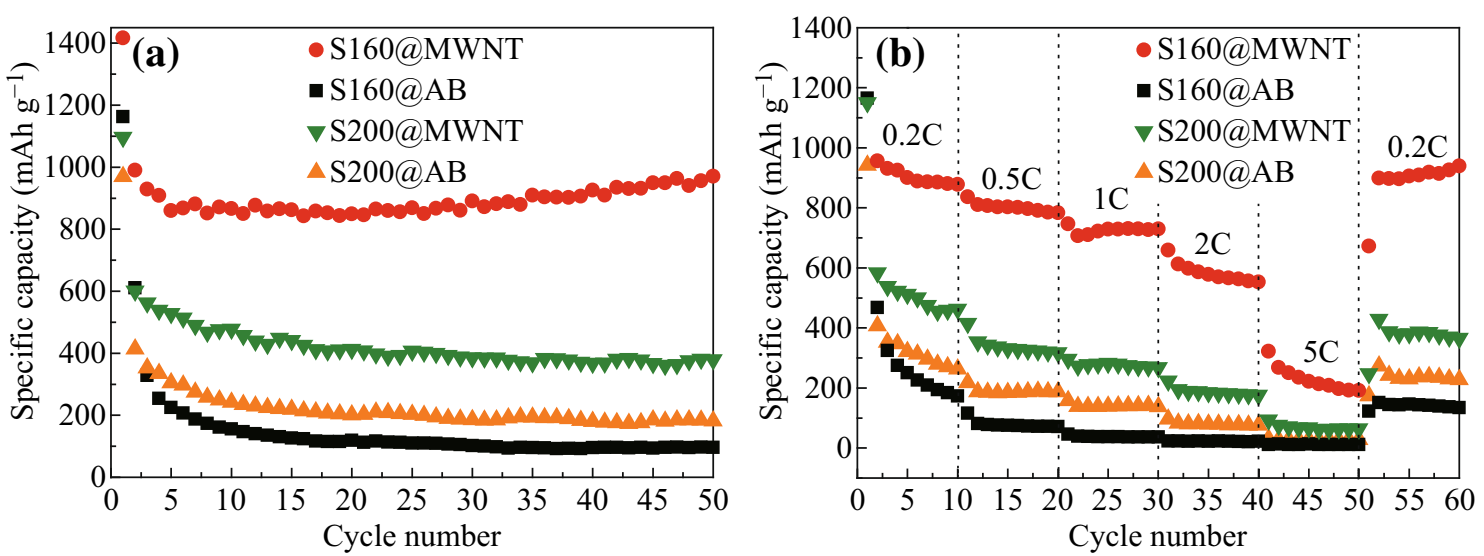

Fig. 4 a Capacity retention of S160@MWNT (2.04 mg)/Li, S160@AB (2.22 mg)/Li, S200@MWNT (2.1 mg)/Li, and S200@ AB (2.4 mg)/Li cells cycled between 0.01 and $3 \mathrm{~V}$ at $0.2 \mathrm{C}$ rate. b Rate capabilities of S160@MWNT (1.86 mg)/Li, S160@AB (2.04 mg)/Li, S200@MWNT $(2.34 \mathrm{mg}) / \mathrm{Li}$, and $\mathrm{S} 200 @ \mathrm{AB}(1.92 \mathrm{mg}) / \mathrm{Li}$ cells at different rates: $0.2,0.5,1,2,5 \mathrm{C}$

to those of the S200@MWNT/Li cell. This is because the two-dimensional $\mathrm{Fe}_{3} \mathrm{O}_{4}$ belt presents a finite lateral size and enhanced open-edges, which facilitate lithium-ion and electron diffusion through active materials and better withstand the large volume change during the charge/discharge process [32, 33]. However, the electrochemical performances of S160@AB/Li and S200@AB/Li cells seem to run counter to the above trend, hinting at the presence of morphology-matching principle for the electrode materials. Under the condition of any given type of conductive agent, the contact degree of the conductive agent and anode material actually determines the LIBs electrochemical performances. In comparison to polyhedral $\mathrm{Fe}_{3} \mathrm{O}_{4}$ particles, the rigid $\mathrm{Fe}_{3} \mathrm{O}_{4}$ belts cannot integrate $\mathrm{AB}$ particulates well (Fig. 1g) and hence resulting in the worst cyclability and rate capability (Fig. 4).

To further validate the above analysis, EIS measurements of S160@MWNT/Li, S160@AB/Li, S200@MWNT/ $\mathrm{Li}$, and S200@AB/Li cells after 50th-cycled capacity retention test (Fig. 5a) and 60th-cycled rate capability test (Fig. 5b) were conducted to examine the kinetics of lithiumion transfer by using a CHI660D electrochemical workstation. The impedance of the electrochemical system was interpreted in terms of Nyquist plots, which describe the gain and phase of the frequency response in polar coordinates. The Nyquist plots for these four cells in two cases are shown in Fig. 5, which were acquired individually under their open-circuit voltage state. Each plot consists of a semicircle in the high-frequency region and a sloping line in the low frequency, which was attributed to the charge transfer process and the mass transfer of lithium ions, respectively. The electrochemical system can be simply fitted by equivalent circuits in the insets of Fig. 5 , where $R_{\Omega}$ is the ohmic resistance, $R_{\mathrm{CT}}$ is the charge transfer resistance, $Z_{\mathrm{Q}}$ is the constant phase element. The fitting results are summarized in Table 1. At very high frequencies (above $10 \mathrm{kHz}$ ), only the ohmic resistance can be observed, which is mainly due to external connections, contact resistance,
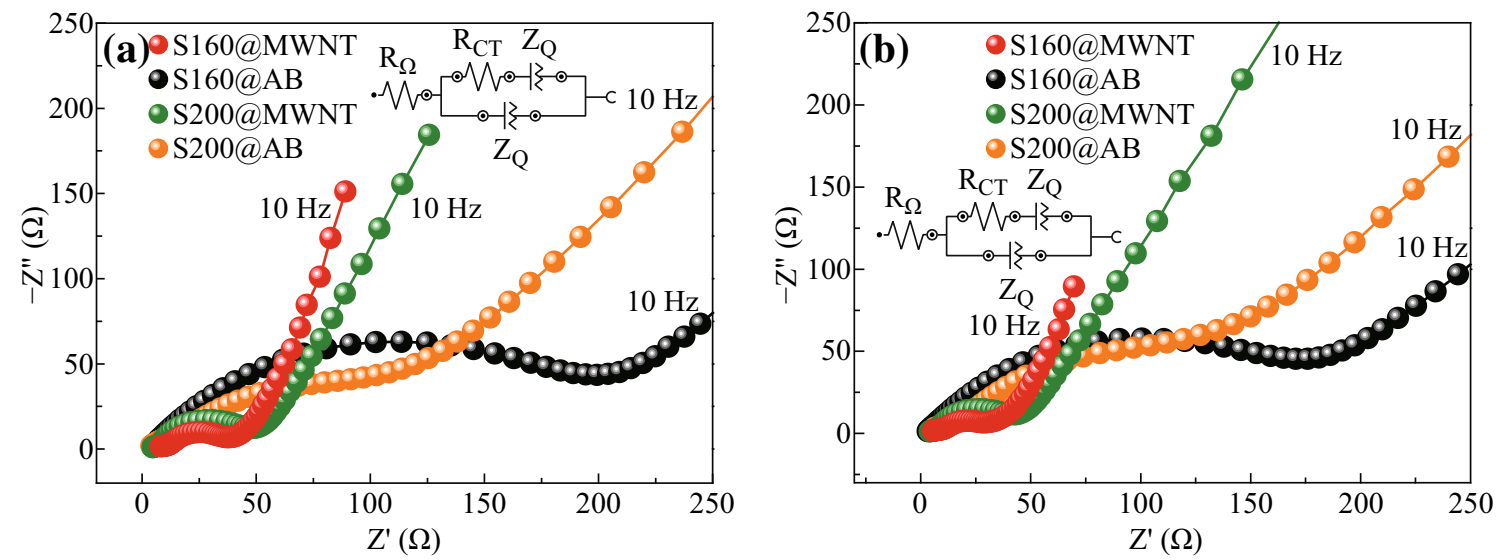

Fig. 5 Electrochemical impedance spectroscopy of the cells after a 50th-cycled capacity retention test and b 60th-cycled rate capability test. Insets equivalent circuits used to fit the impedance data 
Table 1 Electrochemical impedance spectroscopy fitting results for cells after 50thcycled capacity retention and 60th-cycled rate capability test

\begin{tabular}{llclcc}
\hline Resistance $(\Omega)$ & & S160@MWNT & S160@AB & S200@MWNT & S200@ AB \\
\hline After 50th-cycled & $R_{\Omega}$ & 6.48 & 3.83 & 3.73 & 2.74 \\
Capacity retention test & $R_{\mathrm{CT}}$ & 27.1 & 214 & 44.7 & 122 \\
After 60th-cycled rate & $R_{\Omega}$ & 1.41 & 2.63 & 2.69 & 2.75 \\
Capability test & $R_{\mathrm{CT}}$ & 22.3 & 197 & 37.8 & 146 \\
\hline
\end{tabular}

and ionic conduction within the electrolyte [18]. Because of the same electrolyte and identical cell configurations, all electrodes have a similar value of $R_{\Omega}$ for the ohmic resistance (below $7 \Omega$ ) obtained from the fitting results, and this can be easily ascertained from the high-frequency intercept with the real axis ( $\mathrm{Z}$ axis) in the Nyquist plots. A semicircle appears in the frequency region from $10 \mathrm{~Hz}$ to $10 \mathrm{kHz}$ for each cell, which can be attributed to an interfacial charge transfer. The charge transfer resistance can also be determined by fitting the equivalent circuits or directly measuring the diameter of the semicircle in the Nyquist plots. From Table 1, the order from small to large $R_{\mathrm{CT}}$ values is S160@MWNT/Li, S200@MWNT/Li, S200@AB/Li, and $\mathrm{S} 160 @ \mathrm{AB} / \mathrm{Li}$ cells, indicating that the electron transfer would be much easier with the presence of tubular conductive agent. Thereby, based on the EIS measurements, the order from superior to inferior electrochemical performances of these cells is predicted as $\mathrm{S} 160 @ \mathrm{MWNT} / \mathrm{Li}$, S200@MWNT/Li, S200@AB/Li, and S160@AB/Li cells, which is in excellent consistency with the conclusion deduced from Fig. 5.

\section{Conclusions}

In summary, we utilize granular and belt-like $\mathrm{Fe}_{3} \mathrm{O}_{4}$ anode materials and two types of conductive agents (including $\mathrm{AB}$ and MWNT) as prototype systems to investigate their morphology impact on lithium storage performances. We find that the morphology of conductive agent plays a decisive role on electrochemical performances. After 50th cycle, the capacity of MWNT-involved cells (i.e., $970 \mathrm{mAh} \mathrm{g}^{-1}$ for S160@MWNT/Li cell and $380 \mathrm{mAh} \mathrm{g}^{-1}$ for S200@MWNT/Li cell) is much higher than that of the AB-involved cells (i.e., 182 and $96 \mathrm{mAh} \mathrm{g}^{-1}$ for S200@AB/Li and S160@AB/Li cells, respectively). Provided that the morphology of conductive agent of each cell is identical, the electrochemical performances of these cells are mainly determined by the morphology of anode material as well as the contact degree of these electrode materials.

Acknowledgments The authors are grateful to the financial aid from the National Natural Science Foundation of China (NSFC No. $51472133)$.
Open Access This article is distributed under the terms of the Creative Commons Attribution 4.0 International License (http://creativecommons.org/licenses/by/4.0/), which permits unrestricted use, distribution, and reproduction in any medium, provided you give appropriate credit to the original author(s) and the source, provide a link to the Creative Commons license, and indicate if changes were made.

\section{References}

1. L.G. Lu, X.B. Han, J.Q. Li, J.F. Hua, M.G. Ouyang, A review on the key issues for lithium-ion battery management in electric vehicles. J. Power Sources 226, 272-288 (2013). doi:10.1016/j. jpowsour.2012.10.060

2. L. Zhang, H.B. Wu, X.W. Lou, Iron-oxide-based advanced anode materials for lithium-ion batteries. Adv. Energy Mater. 4(4), 1300958 (2014). doi:10.1002/aenm.201300958

3. Y. Tang, Y. Zhang, J. Deng, J. Wei, H.L. Tam, B.K. Chandran, Z. Dong, Z. Chen, X.D. Chen, Mechanical force-driven growth of elongated bending $\mathrm{TiO}_{2}$-based nanotubular materials for ultrafast rechargeable lithium ion batteries. Adv. Mater. 26(35), 6111-6118 (2014). doi:10.1002/adma.201402000

4. S. Chandrashekar, N.M. Trease, H.J. Chang, L.S. Du, C.P. Grey, A. Jerschow, $\mathrm{Li}$ MRI of $\mathrm{Li}$ batteries reveals location of microstructural lithium. Nat. Mater. 11, 311-315 (2012). doi:10. 1038/nmat3246

5. R. Teki, K.D. Moni, R. Krishnan, C.P. Thomas, T.M. Lu, N.K. Prashant, N. Koratkar, Nanostructured silicon anodes for lithium ion rechargeable batteries. Small 5(20), 2236-2242 (2009). doi:10.1002/smll.200900382

6. Y.L. Ding, Y. Wen, C.C. Chen, P.A. Aken, J. Maier, Y. Yu, Nanosheets of earth-abundant jarosite as novel anodes for highrate and long-life lithium ion batteries. ACS Appl. Mater. Interfaces 7(19), 10518-10524 (2015). doi:10.1021/acsami.5b01992

7. M. Madian, L. Giebeler, M. Klose, T. Jaumann, M. Uhlemann, A. Gebert, S. Oswald, N. Ismail, A. Eychmüller, J. Eckert, Selforganized $\mathrm{TiO}_{2} / \mathrm{CoO}$ nanotubes as potential anode materials for lithium ion batteries. ACS Sustain. Chem. Eng. 3(5), 909-919 (2015). doi:10.1021/acssuschemeng.5b00026

8. J.K. Hwang, C. Jo, M.G. Kim, J. Chun, E. Lim, S. Kim, S. Jeong, Y. Kim, J. Lee, Mesoporous $\mathrm{Ge} / \mathrm{GeO}_{2} /$ carbon lithium-ion battery anodes with high capacity and high reversibility. ACS Nano 9(5), 5299-5309 (2015). doi:10.1021/acsnano.5b00817

9. J.M.D. Coey, A.E. Berkowitz, L. Balcells, F.F. Putris, F.T. Parker, Magnetoresistance of magnetite. Appl. Phys. Lett. 72, 734 (1998). doi:10.1063/1.120859

10. P.L. Taberna, S. Mitra, P. Poizot, P. Simon, J.M. Tarascon, High rate capabilities $\mathrm{Fe}_{3} \mathrm{O}_{4}$-based $\mathrm{Cu}$ nano-architectured electrodes for lithium-ion battery applications. Nat. Mater. 5, 567-573 (2006). doi:10.1038/nmat1672

11. B. Wang, H.B. Wu, L. Zhang, X.W. Lou, Self-Supported construction of uniform $\mathrm{Fe}_{3} \mathrm{O}_{4}$ hollow microspheres from nanoplate building blocks. Angew. Chem. 52(15), 4165-4168 (2013). doi:10.1002/anie. 201300190 
12. Q.Q. Xiong, J.P. Tu, Y. Lu, J. Chen, Y.X. Yu, Y.Q. Qiao, X.L. Wang, C.D. Gu, Synthesis of hierarchical hollow-structured single-crystalline magnetite $\left(\mathrm{Fe}_{3} \mathrm{O}_{4}\right)$ microspheres: the highly powerful storage versus lithium as an anode for lithium ion batteries. J. Phys. Chem. C 116(10), 6495-6502 (2012). doi:10.1021/ jp3002178

13. Y. Shi, M. Shi, Y. Qiao, J. Tu, H. Chen, $\mathrm{Fe}_{3} \mathrm{O}_{4}$ nanobelts: one-pot and template-free synthesis, magnetic property, and application for lithium storage. Nanotechnology 23(39), 395601 (2012). doi:10.1088/0957-4484/23/39/395601

14. T. Zhu, J.S. Chen, X.W. Lou, Glucose-assisted one-pot synthesis of $\mathrm{FeOOH}$ nanorods and their transformation to $\mathrm{Fe}_{3-}$ $\mathrm{O}_{4} @$ Carbon nanorods for application in lithium ion batteries. J. Phys. Chem. C 115(19), 9814-9820 (2011). doi:10.1021/ jp2013754

15. L. Wang, Y. Yu, P.C. Chen, D.W. Zhang, C.H. Chen, Electrospinning synthesis of $\mathrm{C} / \mathrm{Fe}_{3} \mathrm{O}_{4}$ composite nanofibers and their application for high performance lithium-ion batteries. J. Power Sources 183(2), 717-723 (2008). doi:10.1016/j.jpowsour.2008. 05.079

16. M. Nishizawa, K. Mukai, S. Kuwabata, C.R. Martin, H. Yoneyama, Template synthesis of polypyrrole-coated spinel $\mathrm{LiMn}_{2} \mathrm{O}_{4}$ nanotubules and their properties as cathode active materials for lithium batteries. J. Electrochem. Soc. 144(6), 1923-1927 (1997). doi:10.1149/1.1837722

17. B. Wang, J.S. Chen, H.B. Wu, Z. Wang, X.W. Lou, Quasiemulsion-templated formation of $\alpha-\mathrm{Fe}_{2} \mathrm{O}_{3}$ hollow spheres with enhanced lithium storage properties. J. Am. Chem. Soc. 133(43), 17146-17148 (2011). doi:10.1021/ja208346s

18. Y.M. Lin, P.R. Abel, A. Heller, C.B. Mullins, $\alpha-\mathrm{Fe}_{2} \mathrm{O}_{3}$ nanorods as anode material for lithium ion batteries. J. Phys. Chem. Lett. 2(22), 2885-2891 (2011). doi:10.1021/jz201363j

19. M.V. Reddy, T. Yu, C.H. Sow, Z.X. Shen, C.T. Lim, G.V.S. Rao, B.V.R. Chowdari, $\alpha-\mathrm{Fe}_{2} \mathrm{O}_{3}$ nanoflakes as an anode material for Li-ion batteries. Adv. Funct. Mater. 17(15), 2792-2799 (2007). doi:10.1002/adfm.200601186

20. H. Wang, H.S. Casalongue, Y. Liang, H. Dai, $\mathrm{Ni}(\mathrm{OH})_{2}$ nanoplates grown on graphene as advanced electrochemical pseudocapacitor materials. J. Am. Chem. Soc. 132(21), 7472-7477 (2010). doi:10.1021/ja102267j

21. J. Liu, Y. Li, R. Ding, J. Jiang, Y. Hu, X. Ji, Q. Chi, Z. Zhu, X. Huang, Carbon/ZnO nanorod array electrode with significantly improved lithium storage capability. J. Phys. Chem. C 113(13), 5336-5339 (2009). doi:10.1021/jp900427c

22. J.Z. Wang, C. Zhong, D. Wexler, N.H. Idris, Z.X. Wang, L.Q. Chen, H.K. Liu, Graphene-encapsulated $\mathrm{Fe}_{3} \mathrm{O}_{4}$ nanoparticles with 3D laminated structure as superior anode in lithium ion batteries.
Chem. Eur. J. 17(2), 661-667 (2011). doi:10.1002/chem. 201001348

23. G.M. Zhou, D.W. Wang, F. Li, L.L. Zhang, N. Li, Z.S. Wu, L. Wen, G.Q. Lu, H.M. Cheng, Graphene-wrapped $\mathrm{Fe}_{3} \mathrm{O}_{4}$ anode material with improved reversible capacity and cyclic stability for lithium ion batteries. Chem. Mater. 22(18), 5306-5313 (2010). doi:10.1021/cm101532x

24. Y. He, L. Huang, J.S. Cai, X.M. Zheng, S.G. Sun, Structure and electrochemical performance of nanostructured $\mathrm{Fe}_{3} \mathrm{O}_{4} /$ carbon nanotube composites as anodes for lithium ion batteries. Electrochim. Acta 55(3), 1140-1144 (2010). doi:10.1016/j.electacta. 2009.10.014

25. T.Q. Wang, X.L. Wang, Y. Lu, Q.Q. Xiong, X.Y. Zhao, J.B. Cai, S. Huang, C.D. Gu, J.P. Tu, Self-assembly of hierarchical $\mathrm{Fe}_{3} \mathrm{O}_{4}$ microsphere/graphene nanosheet composite: towards a promising high-performance anode for Li-ion batteries. RSC Adv. 4, 322-330 (2014). doi:10.1039/C3RA45268A

26. Q.M. Su, D. Xie, J. Zhang, G.H. Du, B.S. Xu, In situ transmission electron microscopy observation of the conversion mechanism of $\mathrm{Fe}_{2} \mathrm{O}_{3}$ /graphene anode during lithiation-delithiation processes. ACS Nano 7(10), 9115-9121 (2013). doi:10.1021/nn403720p

27. P. Poizot, S. Laruelle, S. Grugeon, L. Dupont, J.M. Tarascon, Nano-sized transition-metal oxides as negative-electrode materials for lithium-ion batteries. Nature 407, 496-499 (2000). doi:10. $1038 / 35035045$

28. L.W. Ji, Z. Lin, M. Alcoutlabi, X.W. Zhang, Recent developments in nanostructured anode materials for rechargeable lithium-ion batteries. Energy Environ. Sci. 4, 2682-2699 (2011). doi:10.1039/c0ee00699h

29. J. Cabana, L. Monconduit, D. Larcher, M.R. Palacin, Beyond intercalation-based Li-ion batteries: the state of the art and challenges of electrode materials reacting through conversion reactions. Adv. Mater. 22(35), E170-E192 (2010). doi:10.1002/ adma.201000717

30. P.G. Bruce, B. Scrosati, J.M. Tarascon, Nanomaterials for rechargeable lithium batteries. Angew. Chem. Int. Ed. 47(16), 2930-2946 (2008). doi:10.1002/anie.200702505

31. W.M. Zhang, X.L. Wu, J.S. Hu, Y.G. Guo, L.J. Wan, Carbon coated $\mathrm{Fe}_{3} \mathrm{O}_{4}$ nanospindles as a superior anode material for lithium-ion batteries. Adv. Funct. Mater. 18(24), 3941-3946 (2008). doi:10.1002/adfm.200801386

32. J.S. Chen, X.W. Lou, $\mathrm{SnO}_{2}$ and $\mathrm{TiO}_{2}$ nanosheets for lithium-ion batteries. Mater. Today 15(6), 246-254 (2012). doi:10.1016/ S1369-7021(12)70115-3

33. J.S. Chen, L.A. Archer, X.W. Lou, $\mathrm{SnO}_{2}$ hollow structures and $\mathrm{TiO}_{2}$ nanosheets for lithium-ion batteries. J. Mater. Chem. 21, 9912-9924 (2011). doi:10.1039/c0jm04163g 